\title{
Turismo e Idosos: o patrimônio imaterial como fator de atração para o turismo cultural no espaço rural
}

\section{Tourism and elderly: intangible heritage as a factor of attraction for cultural tourism in rural areas}

\author{
Lívia Morais Garcia Lima ${ }^{1}$ \\ Olga Rodrigues de Moraes von Simson ${ }^{2}$
}

\begin{abstract}
Resumo
A pesquisa tem por objetivo investigar e analisar as formas pelas quais propriedades rurais históricas paulistas se preocupam em proporcionar atividades voltadas para idosos, trabalhando o turismo cultural com uma preocupação voltada à educação patrimonial nãoformal e sob um enfoque qualitativo. O método biográfico ou da História Oral é utilizado tanto para a coleta de informações sobre o patrimônio imaterial, como para levantar as demandas do público idoso. Ela é sempre acompanhada da realização de um diário de campo em associação com registros fotográficos das atividades educacionais e turísticas observadas em duas fazendas selecionadas. Para melhor avaliar programas para o público idoso é necessário uma efetiva conexão entre os elementos encontrados em cada fazenda participante, visando à articulação de ações efetivas para o turismo cultural no espaço rural e às diretrizes da Gerontologia.
\end{abstract}

Palavras-chave: turismo cultural; fazendas históricas; gerontologia; história oral.

\begin{abstract}
The research aimed to investigate and analyze the ways the São Paulo historical rural properties worries in provide activities for the leisure of elderly, working the cultural tourism with a concern of non-formal patrimonial education and under a qualitative focus. The Oral History method was used for gathering information about the intangible heritage and collect the demands of the elderly public. The collect of testimonials was accompanied by the execution of a field journal in association with a photographic register of the educational and tourist activities, as observed in two selected farms. To better evaluate programs for the elderly public need an effective connection between the elements found in each participating farm, designed to articulate effective strategies for cultural tourism in rural areas and the guidelines of Gerontology.
\end{abstract}

Keywords: cultural tourism; historical farms; gerontology; oral history.

\footnotetext{
${ }^{1}$ Doutoranda em Educação pela Universidade Estadual de Campinas (UNICAMP). Mestre em Gerontologia pela UNICAMP. Bacharel em Turismo pela UNESP. Email: liviaomorais@hotmail.com.

${ }^{2}$ Doutora em Sociologia pela Universidade de São Paulo (USP). Docente da Universidade Estadual de Campinas e Pesquisadora do Centro de Memória da UNICAMP. Email: simson@superig.com.br.
} 


\section{Introdução}

Foi pensando no turismo, enquanto meio propulsor de experiências no âmbito do lazer e da cultura, que decidimos desenvolver a pesquisa que analisa as formas pelas quais os responsáveis por espaços históricos e de visitação se preocupam em criar e incentivar as atividades culturais voltadas para idosos.

Nas últimas décadas, estudos e projeções estatísticas mundiais vêm demonstrando "o crescente envelhecimento populacional em países desenvolvidos e de maneira substancial em países subdesenvolvidos" (HOOVER e SIEGEL, 1986, p. 35). Para muitos pesquisadores o grande desafio para os países de Terceiro Mundo, que são carentes em vários aspectos, é fornecer melhoria de qualidade de vida aos que já envelheceram e aos que estão no processo de envelhecimento.

Conforme estimativas para o ano de 2050, países escolhidos para efeito de comparação internacional, conhecidos como BRICS (Brasil, Rússia, Índia, China e África do Sul) "possuirão ao todo cerca de 273 milhões de pessoas de 60 anos ou mais de idade, o que corresponde a 40,6\% da população idosa mundial" (IBGE, 2008). No Brasil, entre 1950 e 2025, a população, como um todo, crescerá em torno de cinco vezes, enquanto que o crescimento da população idosa será da ordem de quinze vezes. Assim, “o Brasil será em 2025 a sexta maior população de idosos no mundo.” (KALACHE e GRAY, 1985, p. 51).

Segundo Campos (2003) "o entendimento do que seja o lazer e o turismo na terceira idade necessita da compreensão da velhice como continuidade de um processo natural da vida e da heterogeneidade bio-psico-social do indivíduo que a vivencia”. Ampliando esse conceito da Gerontologia $^{3}$, podemos dizer que a velhice é construída pela estrutura biológica de um indivíduo, por seu capital cultural e social e por suas crenças e valores, como um resultado de tudo aquilo que vivenciou. Faz parte da noção de heterogeneidade da velhice a proposta de vê-la como um fenômeno não só biológico, mas também como uma etapa da vida construída socialmente e encarar o velho consciente de sua importância como sujeito social. Mercadante (1998) afirma que "pensar a velhice de maneira não total é estabelecer uma determinação do

\footnotetext{
${ }^{3}$ A Gerontologia pode ser definida como multi e interdisciplinar que estuda o processo de envelhecimento, o fenômeno da velhice, enquanto evento de natureza biológica, sociológica e psicológica e os indivíduos e os grupos socialmente definidos como idosos (NERI, 1993, p. 28).
} 
biológico sobre todos os outros aspectos que explicam o envelhecimento", ou seja, não devemos restringir a velhice apenas a análise de suas características biológicas.

Assim, apesar de considerar o crescente número de idosos integrando a sociedade brasileira juntamente com os outros segmentos etários, estamos procurando investigar as novas interpretações e formas de uso cultural do lazer, através da educação não - formal associada ao envelhecimento. Segundo Neri (2008, p. 36) "uma das importantes necessidades afetivas dos idosos é a alegria, que se associa à exploração do ambiente, por exemplo, por meio do lazer". A autora ainda ressalta que a promoção da boa qualidade de vida na idade madura excede os limites da responsabilidade pessoal e deve ser vista como um empreendimento de caráter sócio-cultural. Isto resulta, portanto, não só do estado biológico, mas também das condições existentes para um envelhecimento bem sucedido, o que envolve contatos pessoais e sociais, fora dos limites de seu espaço cotidiano.

Propomos, portanto, discutir perspectivas para a melhoria da qualidade de vida do cidadão idoso voltadas para o uso cultural do lazer, por meio de propostas de atividades de educação patrimonial e turismo cultural, no contexto das fazendas históricas paulistas, selecionadas pelo projeto em Políticas Públicas em andamento denominado: Patrimônio Cultural Rural Paulista: espaço privilegiado para pesquisa, educação e turismo (Fundação de Amparo à Pesquisa do Estado de São Paulo - FAPESP/ Centro de Memória da Universidade Estadual de Campinas CMU), fase 2, ao qual esta pesquisa está vinculada.

O projeto FAPESP/CMU reúne dezoito propriedades em regiões significativas do Estado de São Paulo, sendo essas definidas pelos núcleos regionais compostos pelas cidades de Campinas, Limeira-Rio Claro, São Carlos-Araraquara, Itu, Mococa- Casa Branca e Vale do Paraíba. A atual pesquisa selecionou duas fazendas, das dezoito integrantes definidas a partir do universo abrangido pelo projeto em políticas públicas.

O objetivo geral é investigar e analisar as formas pelas quais as propriedades rurais históricas paulistas se preocupam em proporcionar atividades voltadas para idosos, trabalhando o turismo cultural no espaço rural com uma preocupação voltada à educação patrimonial nãoformal e sob um enfoque qualitativo. O método biográfico ou da História Oral é utilizado tanto para a coleta de informações sobre o patrimônio imaterial, como para levantar as demandas do público idoso. Ela é sempre acompanhada da realização de um diário de campo 
em associação com registros fotográficos das atividades educacionais e turísticas observadas em duas fazendas selecionadas.

De modo geral as fazendas históricas do interior de São Paulo são possuidoras de um passado que lhes confere riqueza histórica e cultural únicas. Segundo Faustino (2006), "as propriedades possuem paisagem típica rural e podem ser denominadas como estruturas patrimoniais com significados específicos". Algumas podem ser mais privilegiadas como fazendas onde se hospedaram o Imperador Dom Pedro II, sendo assim, possuidoras de relíquias da época imperial, como arquitetura, mobiliários, jóias, festas, causos, culinária, o que lhes confere um sentido de valor único. $\mathrm{O}$ autor ainda ressalta que o turismo se utiliza e enfatiza justamente este patrimônio único, o que faz com que cada vez mais turistas se interessem por querer desfrutar da beleza cênica e da história do lugar. Assim o turista e o patrimônio cultural entram em sintonia, através de uma intensa interpretação dos signos locais o que permite a redescoberta de um passado, às vezes contrastante com o presente, mas sempre cheio de fatos eloqüentes.

Tratar as fazendas históricas paulistas como um objeto cultural, tematizando, a partir delas, uma série de referências e valores simbólicos para os grupos de idosos, é também um dos desafios da pesquisa que gerou este artigo.

Em um primeiro momento, discorremos sobre o entendimento do que seja o lazer e o turismo na velhice e a idéia de que o turismo, especificamente o turismo cultural pode estar associado a outras atividades turísticas, como uma atividade de lazer educacional que contribui para aumentar a consciência do visitante e sua apreciação da cultura local. Dessa maneira, trazemos para a discussão teórica o conceito de educação não-formal. Em seguida, explicamos a metodologia qualitativa da História Oral utilizada como base para a obtenção de informações que permitem estruturar o turismo cultural, definindo os espaços de pesquisa, tanto materiais quanto imateriais.

Na conclusão, retomamos a idéia de que a pesquisa passa pela discussão da condição do velho frágil, versus aquela do velho ativo, criado pela "ditadura" da juventude, imposta pela sociedade atual que quer transformar todo velho em um velho participante. Ressaltamos assim, que trabalhamos a relação velhice e turismo em uma perspectiva educacional não - 
formal e não apenas na perspectiva operacional como é feito nas áreas mais tradicionais do turismo, como a da gestão hoteleira ou a da administração das empresas turísticas.

\section{Lazer e Turismo: fenômenos do tempo livre}

A realização de atividades de turismo cultural e de educação patrimonial não - formal nas fazendas históricas paulistas objetiva um reconhecimento tanto do imóvel rural e seu entorno, quanto dos bens imateriais a ele relacionado. Além de seus atributos arquitetônicos e paisagístico, a sua excepcionalidade e a sua historicidade, os tornam reconhecíveis como bens culturais. Esse processo pretende, ao dar a conhecer a propriedade e seus bens tangíveis e intangíveis, qualificá-la como patrimônio, inserindo-a na história e nas redes de valor cultural, otimizando assim a experiência de visitação de grupos de idosos. A pesquisa vem possibilitando, a partir da recuperação das propriedades rurais como bens culturais, resignificar práticas e representações sociais que nelas ocorrem. A meta da interpretação sóciocultural desse rico patrimônio paulista é estabelecer uma rede de descobertas para o visitante idoso, estimulando o seu olhar, provocando a curiosidade e levando-o a descobrir muito mais sobre o lugar e seus habitantes, sua história, suas lendas, que valorizam as atrações naturais e culturais das fazendas históricas, estabelecendo assim uma comunicação efetiva com o visitante e mantendo desse modo importantes interfaces com o lazer e o turismo cultural ao agregar valor histórico-cultural ao que se tornou um produto turístico.

O lazer é um conjunto de ocupações às quais o indivíduo pode entregar-se de livre vontade, seja para repousar, seja para divertir-se, recrear-se e entreterse ou, ainda para desenvolver sua informação ou formação desinteressada, sua participação social voluntária ou sua livre capacidade criadora, após livrar-se ou desembaraçar-se das obrigações profissionais, familiares e sociais. (DUMAZEDIER, 1994)

Esta reflexão sobre o turismo como dimensão importante para o desenvolvimento humano vai ao encontro da abordagem feita por Harahousou (2000, p. 33) sobre lazer de idosos, "lembrando que as experiências de lazer oferecem oportunidades para interação social de forma produtiva e, por extensão, conduzem aos benefícios da socialização”. A autora considera que a disponibilidade de tempo livre permite que se aprendam novas atividades e se 
desenvolvam novos interesses, como parte de um grupo. Souza (2002) completa esta idéia ressaltando que "para se usufruir da velhice é preciso dispor de políticas adequadas que possam garantir o mínimo de condições de qualidade de vida, para os que atingem a velhice e sem dúvida, o lazer representa um marco importante nessa disponibilidade”.

O lazer, portanto, se opõe à idéia de obrigação se reafirmando como fator de reequilíbrio psicossomático e de desenvolvimento pessoal e sociocultural, além da formação, também oferece possibilidades de integração a instituições sociais e culturais e, ainda o desenvolvimento de novas habilidades. Bacal (2003) enfatiza que "o lazer também se caracteriza pela realização de atividades de livre - arbítrio que se efetivam nesse tempo livre". Essas atividades dentre os lazeres, com destaque para o lazer turístico, são vistas como um fim em si mesmas, despertando no indivíduo sentimentos de bem - estar e satisfação. Dumazedier ainda revela em seus estudos que:

Em casas de retiro, nos lares, nos clubes, descobre-se cada vez mais que a maioria dos aposentados, válidos ou não, abastados ou pobres, está principalmente em situação de lazer e que as atividades novas se desenvolvem apesar da insuficiência do interesse ou dos preconceitos (DUMAZEDIER, 1994).

É através da prática destas atividades, através dos valores correspondentes que as probabilidades de realização pessoal na velhice são mais fortemente prováveis.

O estudo realizado por Souza, Melo e Widmer (2008), afirmam que em viagens curtas ou passeios de apenas um dia de duração, idosos têm diferentes tipos de expectativas. Desejam fazer novas amizades, descansar ou participar de atividades físicas. Assim, baseados nos resultados obtidos, as autoras oferecem às empresas que organizam viagens para idosos, algumas sugestões como viagens que ofereçam passeios a locais de interesse históricocultural, e que os guias forneçam explicações sobre a história do local visitado. Isso vem de encontro com o objetivo da presente pesquisa, trabalhando o turismo cultural no espaço rural visando atividades sócio-culturais que sejam educativas e prazerosas e considerando o meio rural como uma experiência diferenciada de lazer para os idosos e as fazendas históricas como o atrativo turístico. 
O turismo é um fenômeno extremamente complexo, mutável, que opera de múltiplas formas e nas mais diversas circunstâncias, sendo difícil apreendêlo, em sua totalidade, por meio de uma única perspectiva teórica ou mesmo de uma única ciência (JÚNIOR, 2001)

O autor afirma que para estudar o fenômeno turístico é necessário diferenciar os seus diversos tipos e atentar para que tipos de interferência e reações esses diferentes tipos de turismo provocam nas culturas em que atuam. A atual pesquisa se preocupou em definir o turismo cultural $^{4}$ no espaço rural estabelecendo uma relação com os espaços históricos das fazendas paulistas selecionadas, produzindo assim um conhecimento mais amplo do turismo como fenômeno social. Portanto, nesse artigo buscamos fazer uma crítica ao crescimento do mercado turístico que acompanha a criação de uma nova linguagem em oposição às antigas formas de tratamento dos velhos: a terceira idade ou a melhor idade substitui o termo velhice; a aposentadoria ativa se opõe à aposentadoria inativa; o asilo passa a ser chamado de centro residencial. Os significados do envelhecimento são invertidos e assumem novas designações: nova juventude, idade do lazer, idade de ouro ${ }^{5}$. Da mesma forma, invertem-se os signos da aposentadoria, que deixa de ser um momento de descanso e recolhimento, para tornar-se um período de constante atividade, em que o velho torna-se somente um consumidor em potencial.

O uso da designação "terceira idade" ou "melhor idade" ao invés de velhice vêm provocar um novo sentido que seria o sentido da não-velhice, negando o significado histórico da velhice como declínio, incapacidade, fragilidade e como fase de resignação às perdas da beleza e da capacidade físico-cognitiva.

\section{Envelhecimento, Turismo Cultural e Educação não-formal}

O turismo bem - sucedido vai muito além do transporte confiável e de hotéis confortáveis. $\mathrm{Na}$ avaliação de Goeldner $(2002,72)$ "é necessário o aprimoramento de todos os caminhos

\footnotetext{
${ }^{4}$ Entende-se por turismo cultural todo turismo em que o principal atrativo não seja a natureza, mas algum aspecto da cultura humana. (BARRETO, 2000, p. 20)

${ }^{5}$ Tais termos, utilizados em vários programas gestados pelo poder público ou por empresas turísticas, fugindo dos termos velho ou idoso, tentam ideologicamente afastar a realidade da velhice vendendo a idéia de que o lazer rejuvenesce.
} 
através dos quais uma localidade se apresenta, entre eles estão as atividades educacionais, científicas e culturais".

Dessa maneira, "o turismo cultural é baseado no patrimônio histórico, arquitetônico, cultural e artístico enquanto produto da atividade humana, onde instalações abrem as portas para a exploração do passado" (FAUSTINO, 2006, p. 77) sendo compatível e "comprometido com o fortalecimento da identidade, a preservação da memória e do patrimônio cultural em lugares de destinação turística.” (FREIRE E PEREIRA, 2002, p. 54).

O turismo cultural efetiva-se quando da apropriação de algo que possa ser caracterizado como bem cultural, seja o que for, pois patrimônio cultural é tudo aquilo que constitui um bem apropriado pelo homem, com suas características únicas e particulares. (FUNARI E PINSKY, 2005)

$\mathrm{Na}$ avaliação do autor, o turismo cultural abrange tudo que constitui parte do engenho humano e, por isso, pode estar no cerne do turismo. Assim, toma-se a cultura como componente central dos deslocamentos visando o lazer e como importante instrumento de conscientização social.

Juntamente com os impactos positivos do turismo na economia local, há sempre riscos de danos à natureza e à identidade local, trazidos pelos empreendimentos da área no setor, pois geralmente pequenas comunidades organizadas em torno de práticas culturais muito antigas, se vêem bruscamente alteradas pela chegada de pessoas com estranhos costumes. Assim o turista cultural chega pedindo licença, e procura conhecer a história, não só buscando as evidências materiais do passado, presentes em sítios, monumentos e objetos consagrados como patrimônio, "mas também escutando ou lendo relatos e lembranças dos que vivenciaram e fizeram a história do lugar" (GOODNEY, 2002, p. 43). Por meio do turismo cultural, o patrimônio tem mais condição de se tornar um recurso renovável, pois a atividade turística pressupõe o deslocamento de pessoas para apreciar a cultura de outras localidades e viajar para experimentar, o que permite ao longo do tempo, uma intensificação da economia local pela maior valorização dos bens culturais, sejam eles tangíveis ou intangíveis, mas sempre sob uma perspectiva sustentável. Assim, é necessário se pensar no turismo como um benefício ao patrimônio cultural e ao mesmo tempo levar em conta, os perigos de uma atividade turística descontrolada. Nesse caso, o turismo cultural passa a desencadear um processo de construção 
de relações entre passado e presente o que foi verificado nessas fazendas históricas, fugindo da idéia dos resorts e da artificialidade que os compõem.

Para estabelecer uma relação com os espaços históricos das fazendas:

O turismo cultural voltado para a terceira idade assume um papel educativo alcançando seu ponto culminante no contato direto do indivíduo com seu interesse particular, seja ele um monumento histórico, uma etnia, uma dança, um museu (DIAS, 2006).

O autor ressalta a idéia de que o turismo cultural pode estar associado a outras atividades turísticas, como uma atividade de lazer educacional que contribui para aumentar a consciência do visitante e sua apreciação da cultura local.

Pelo método interpretativo, o lugar, no caso da atual pesquisa as fazendas históricas paulistas, além de se expor naturalmente à apreciação do público, pode falar sobre si mesmo e explicitar sua identidade. Utilizando-se de diferentes fontes de conhecimento e formas de comunicação, o ambiente interpretado convida e facilita ao visitante chegar mais perto, experimentar, interagir, conhecer, aprovar ou criticar a dinâmica cultural daquele contexto. Segundo Freire e Pereira (2002, p. 86) "interpretar o patrimônio é o processo de acrescentar valor à experiência do visitante, por meio do fornecimento de informações e representações que realcem a história e as características culturais e ambientais de um lugar”.

Park (2007, p. 54) ressalta que "as práticas na área da chamada educação não-formal também têm se embasado em trabalhos que privilegiam a memória, pois esta facilita a reconstrução identitária do educando”. Ela aponta que isolamentos culturais podem ser rompidos e a autoestima dos grupos de educandos e de seus familiares sofre crescente valorização, através das experiências educacionais realizadas fora do espaço escolar.

Para que ocorra a proposta de educação não-formal é necessário um local no qual todos tenham espaço suficiente para experimentar atividades lúdicas, estas entendidas como tudo aquilo que provoque a imaginação e seja envolvente e vá ao encontro de interesses, vontades e necessidades de crianças, adultos e idosos, sem preocupação com avaliações ou certificações. (SIMSON, PARK E FERNANDES, 2001) 
Em se tratando da educação não-formal envolvendo grupos de idosos, há uma constante troca de saberes entre esses participantes e os próprios educadores, pois todos pensam na prática a construção de um conjunto de ações, reflexões e produções, devido a uma concepção ampla de educação. Pensando nas atividades de educação patrimonial não-formal, a educação patrimonial tem a missão de criar atividades voltadas para o bem estar da comunidade local, não apenas para que se torne uma localidade viável para a promoção do turismo, "mas principalmente para que também seja despertado em seus moradores o sentimento de valorização da sua história.” (POSSATI, 2005, p. 44). "A preservação do patrimônio pode ser tanto causa, como conseqüência do turismo" (BARRETO, 2001, p. 16), e a prática turística pode constituir um processo de aprendizagem constante, envolvendo as várias gerações de habitantes do local.

É necessário que fiquemos atentos para este patrimônio no sentido de sua preservação, identificação, documentação, proteção, valorização e revitalização dos bens intangíveis, como tradições e expressões orais, expressões artísticas, práticas sociais, atos festivos, técnicas artesanais tradicionais, e "sugere-se que a transmissão desses bens ocorra essencialmente por meio da educação formal e não-formal”. (PELEGRINI \& FUNARI, 2008, p. 28).

Desse ponto de vista, o patrimônio imaterial dá alma aos espaços concretos monumentais sendo transmitido de geração a geração e é conceituado a partir da perspectiva da alteridade, sendo considerado alvo de constantes recriações decorrentes das mutações entre as comunidades e os grupos que convivem num dado espaço social, do meio ambiente, das interações com a natureza e da própria história dessas populações. Em outras palavras, o patrimônio imaterial é o "saber fazer", e o "saber viver" e não o seu produto.

Neste sentido, a educação patrimonial é:

um instrumento de alfabetização cultural que possibilita ao indivíduo fazer a leitura do mundo que o rodeia, levando-o à compreensão do universo sociocultural e da trajetória histórico - temporal em que está inserido (HORTA, 2005). 
Este processo leva ao reforço da auto - estima dos indivíduos e comunidades e à valorização da cultura, compreendida como múltipla e plural. A educação patrimonial é o embasamento teórico em que se abordam, de forma simples os conceitos de cultura, bens culturais, materiais ou imateriais, móveis ou imóveis. Em seguida se propõe um exercício de observação, em que se "evidencia o potencial que qualquer personagem tem como fonte de informação sobre o momento histórico e/ou a sociedade que o criou." (DUARTE,1994). A autora destaca a importância de um processo contínuo de criação cultural, no qual a educação patrimonial busca levar as crianças e os idosos a um processo ativo de apropriação e valorização de sua herança cultural, capacitando-os para um melhor usufruto destes bens, e propiciando a geração e a produção de novos conhecimentos.

Partindo dessa discussão, entendemos que o papel da Educação Patrimonial é o de possibilitar que o patrimônio seja percebido como expressão de uma memória, através das possibilidades e intenções da sua ação educativa, e quais as influências que ele exerce sobre nosso modo de viver, "a fim de que passemos da mera contemplação e do consumo para a apropriação e produção desses bens culturais, como referencias da nossa construção identitária" (AMORIM, 2007, p. 23).

"Independentemente da atuação da escola, a sociedade vem desenvolvendo uma concepção própria de patrimônio, a partir de princípios nem sempre definidos e por meio de uma diversidade de ferramentas". (ZANON, MAGALHÃES E BRANCO, 2009, p. 34). Assim os autores destacam que o turismo apropria-se do patrimônio na sua prática, sendo um dos principais elementos de definição de roteiros e investimentos na área. Neste sentido, este profissional tende a preocupar-se com a questão do patrimônio histórico e cultural, indo além da arquitetura e inserindo, em suas reflexões, elementos como a cultura imaterial, entre eles festas, lendas, causos, costumes e tradições.

Apesar disso, a educação patrimonial é considerada uma questão difícil e atual, considerando a tendência cultural hoje prevalente de crise de memória. A preservação da memória e do patrimônio cultural deve servir como um exercício de educação patrimonial, como forma de sensibilizar os idosos para o compromisso com a memória, com a história e com as próprias ações vivenciadas cotidianamente, na construção da história individual e coletiva. A educação patrimonial trabalhada com o público idoso esclarece e fundamenta o trabalho de 
conhecimento, apropriação e valorização de diferentes culturas, em diferentes lugares e épocas. Dessa forma, é necessário se pensar a educação patrimonial não só como um aspecto a ser trabalhado comumente em escolas, mas também em espaços educacionais não-formais, como é o caso das fazendas históricas selecionadas nessa pesquisa e como fonte de ativação da memória social ${ }^{6}$.

As possibilidades de um trabalho de educação patrimonial não-formal em fazendas históricas paulistas promove a ativação da memória social, construindo a auto-estima dos visitantes idosos, de modo a se identificarem com o patrimônio e o valorizarem como um bem de toda a coletividade.

Assim a pesquisa sobre o Patrimônio Cultural Rural Paulista se torna um trabalho sobre a utilização dos bens culturais como fonte de lazer e turismo, possibilitando um exercício de sensibilização para a valorização dos espaços rurais, a partir da análise das representações dos sujeitos e seus papéis, do imaginário rural, e da decodificação dos valores existentes naquele espaço.

A pesquisa possibilitou a construção de um conhecimento sobre a cultura material e imaterial e sua utilização em atividades de turismo cultural em espaços privados (as fazendas históricas), anteriormente inacessíveis aos pesquisadores das diferentes disciplinas que integram a equipe da pesquisa em políticas públicas FAPESP - CMU. Além disso, trouxe novas contribuições, através de encontros e discussões que envolveram diretamente os proprietários das fazendas históricas. Nessas discussões eles apresentaram as necessidades e expectativas comuns, buscando assim promover no grupo uma tomada de atitudes para minimizar dificuldades encontradas nessas experiências turísticas e demandaram a criação de um modelo que possa ser utilizado no atendimento à população idosa. Segundo Keer (2006) "neste processo em que os pesquisados participam da pesquisa e das discussões que decidem sua realização, acontece um fenômeno denominado empoderamento”.

Frisch (1990, p. 46) conceitua o empoderamento "como um processo que possibilita a aquisição de habilidades e conhecimentos àqueles que estão alijados do poder”. O autor afirma que, a partir de uma prática dialógica o grupo pode conquistar a promoção de uma

\footnotetext{
${ }^{6}$ Trabalhamos com o conceito de memória social a partir do conceito de Halbwachs (1990). A memória social é aquela formada pelos fatos e aspectos julgados relevantes pelos grupos dominantes e que são guardados como memória oficial da sociedade mais ampla.
} 
consciência histórica mais democrática e dessa forma pode se apropriar de uma gama mais profundamente representativa de experiências, perspectivas e valores.

As reconstruções compartilhadas de processos históricos-sociais, via memória oral, podem redundar em argumentos políticos capazes de fornecer um certo poder aos grupos sociais estudados, permitindo a eles ganhos em suas lutas, sejam elas de caráter político, social ou cultural o assim denominado processo de empoderamento (SIMSON, 2008).

A autora afirma que o fator determinante do sucesso desse processo de construção e domínio conjunto de um conhecimento novo, está na capacidade do pesquisador de traduzir as conclusões da investigação científica numa linguagem que seja facilmente compreendida pelo grupo pesquisado.

Neste sentido, as práticas de educação não-formal são encaradas:

como passíveis de serem aplicadas a todos os grupos etários, de todas as classes sociais e em contextos socioculturais diversos, gerando oportunidades de crescimento individual e grupal pela participação em processos de transformação social (SIMSON, PARK \& FERNANDES, 2001).

No caso desta pesquisa, se trata da transformação da realidade dos idosos, que passaram a vivenciar experiências turístico-culturais ligadas ao patrimônio rural paulista em uma abordagem que vem privilegiando as representações simbólicas dos diversos atores envolvidos: proprietários das fazendas, funcionários e visitantes. A questão patrimonial está inexoravelmente ligada à questão cidadã, porque se encontra no cerne da formulação de políticas de definição e preservação; é esta articulação que afasta o enfoque conservador, saudosista, para dar lugar à consciência do uso social dos diversos patrimônios (material e imaterial), inclusive no espaço rural.

Dessa maneira a cultura e o patrimônio não são encarados como produtos turísticos, muitas vezes seguindo planos de viagem equivocados que maximizam o tipo de consumo que denota um uso superficial e mercadológico, mas como elementos de memória e identidades locais, 
possibilitando assim a experiência do turista idoso junto ao patrimônio histórico, no sentido de vivência plena das realidades materiais e imateriais.

Sem programas específicos para cada propriedade rural e que sejam eficazes para comunicar os sentidos do passado e do presente que ela encerra, bem como a atrair visitantes para formas de observação e compreensão, de patrimônios muitas vezes em processo de extinção, há um grande perigo de que o patrimônio cultural seja tão homogeneizado e mercantilizado, que chegue a perder seu potencial de atração educativa para a maioria dos observadores.

\section{História Oral e Turismo Cultural}

A pesquisa utilizou uma metodologia de caráter qualitativo com ênfase no método biográfico ou da História Oral, em associação com registros em diário de campo e a produção de registros fotográficos das visitas observadas.

"A pesquisa qualitativa não utiliza amostras estatísticas, mas sim amostras estatisticamente significativas e aponta direções e encaminha possíveis explicações para os fenômenos sociais em estudo" (LANG, 2001). Na avaliação de Queiroz (1988) "a metodologia da História Oral foi empregada com tanto sucesso pelos cientistas sociais que foi encarada como a técnica por excelência, complementando as metodologias quantitativas". Para a autora, o relato oral sempre foi a maior fonte humana de conservação e difusão do saber e sua transmissão diz respeito tanto ao passado mais longínquo, quanto ao passado muito recente, a experiência do dia-dia.

O método da História Oral, "busca conhecer o passado recorrendo à memória do narrador. Nesse método a rememoração de fatos é empregada no processo de reconstrução da realidade sócio-cultural" (SIMSON, 2008, p. 31). Para a autora, o instante do rememorar implica o lembrar e o imaginar, pois apenas traços destas experiências podem ser reconstruídos; elas nunca serão representadas, trazidas para o presente de novo, tal como ocorreram no passado. Essa rememoração pode ter um caráter mais pessoal e afetivo mas "pode ser também um instrumento político ou um critério de definição da verdade, sendo a memória uma ligação entre passado e presente" (BRITO, 1989). 
O objetivo da História Oral não se limita a ampliação de conhecimentos e informações sobre o passado recente, mas visa conhecê-lo através da versão de pessoas que o viveram. Busca conhecer a sociedade através de testemunhos, construindo documentos que serão submetidos à analise (LANG, 2001).

Assim, realizou-se primeiramente um levantamento do patrimônio imaterial que se apresenta nas fazendas históricas paulistas selecionadas, através de entrevistas abertas para a rememoração dos saberes tradicionais rurais com os proprietários e também com os funcionários mais antigos das fazendas que realizam atividades educacionais e turísticas nessas propriedades. As entrevistas, como já mencionado, foram sempre acompanhadas de observação participante e da realização de um diário de campo. Para a entrevista, elaboramos previamente um roteiro de questões, tendo por base os itens lendas e causos, festas e comemorações, culinária típica da fazenda, atividades musicais, de artesanato e remédios caseiros feitos à base de plantas. Através desse levantamento pudemos conhecer melhor o universo cultural de fazendas históricas e dizer quantas se dedicam ao turismo cultural. Durante a visita também foi realizado o levantamento das atividades turísticas em espaço rural já realizadas no contexto das fazendas visitadas, através de entrevistas com os proprietários e o levantamento das atividades de educação patrimonial, através de entrevistas com proprietários e com os monitores. Davis (2003) "trata o momento da entrevista como um evento interativo, uma performance que envolve as atividades de ambos: o entrevistador e o entrevistado, permitindo compreender a entrevista como uma construção reflexiva".

Para Queiroz (1988, p. 55) "o relato oral se apresenta como técnica útil para registrar o que ainda não se cristalizara em documentação escrita, o não conservado, o que desapareceria se não fosse anotado, serve para captar o não explícito, quem sabe mesmo o indizível", como é o caso do patrimônio imaterial das fazendas históricas.

A História Oral pode captar a experiência efetiva dos narradores, mas também recolhe destes tradições e mitos, narrativas de ficção, crenças existentes no grupo, assim como relatos que contadores de histórias, poetas, cantadores que inventam num momento dado (QUEIROZ, 1988).

Em relação aos registros em diário de campo: 
São nas notas de caderno de campo que estão registrados todos os aspectos da construção da relação entre entrevistador e os vários entrevistados, as percepções e os insigths que aconteceram durante a longa série de contatos e visitas ao campo. (SIMSON E GIGLIO, 2001)

No caso da presente pesquisa, o diário de campo foi um instrumento imprescindível para o registro de observações e as impressões das idas às fazendas históricas, tanto em relação ao contato com os depoentes selecionados como da comunicação com os proprietários e funcionários mais antigos da propriedade.

A escolha de duas fazendas para a realização da pesquisa se justificou pelo fato dos proprietários possuírem formação universitária e incorporarem uma preocupação com a educação patrimonial ao organizar as atividades para idosos que ocorrem nas duas fazendas.

A Fazenda Quilombo, localizada no município de Limeira - SP foi a primeira propriedade selecionada pela pesquisa. Durante as visitas à fazenda foram realizadas primeiramente conversas informais com os idosos que participavam de atividades educacionais e turísticas na propriedade, para posteriormente se efetuar uma análise crítica dos dados levantados. Entretanto, como esse contato foi feito em ocasiões de lazer, a forma de questionário não foi a mais adequada. Utilizamos um rol de questões que serviu de base para a construção de um diálogo de caráter informal e mais leve entre pesquisador e pesquisados, no próprio momento da visita, ou logo após o seu término.

A segunda propriedade selecionada pela pesquisa foi a Fazenda Pinhal, localizada no município de São Carlos - SP. As visitas guiadas à Fazenda Pinhal não são cobradas para crianças e adolescentes de até 18 anos e para o público de idosos, acima de 60 anos. Na nova gestão da propriedade não há mais hospedagem na casa sede e as quatorze unidades habitacionais de hotelaria foram desativadas, a pedido do novo proprietário da Fazenda Pinhal, mas as visitas de grupos de idosos provenientes de centros de conveniência de cidades interioranas se intensificaram.

Posteriormente, foram realizadas entrevistas com temáticas mais amplas com seis idosos que participaram de atividades nas duas propriedades selecionadas, para conhecer as razões que os levaram a buscar esse tipo de lazer, como se sentiram durante a visita, o que mais lhes agradou assim como, o que não correspondeu à sua expectativa e o que os desagradou. 
Neste sentido, delineou-se uma discussão e reflexão da aplicabilidade, ao se estudar qualitativamente a dimensão social do turismo, revelando-o como produção das sociedades humanas e como um processo de interação social, indissociável, portanto, dos seus aspectos históricos e sociais, no sentido de se ampliar o entendimento sobre os fenômenos culturais e sobre as sociedades que os produzem, ouvindo outros atores sociais no turismo de caráter cultural, além dos empresários e proprietários.

Assim, a compreensão da cultura é fundamental no turismo para possibilitar o entendimento do visitante sobre aquilo que é visitado. É necessário que seja dada oportunidade ao cidadão idoso durante essas viagens de reconstruir as suas memórias, para permitir a construção de sua identidade como velho. Ao contrário da visão do idoso, como alguém que se tornou incapaz de produzir, passando a ser visto apenas como um consumidor em potencial, o turismo cultural nessa pesquisa foi entendido como abrangendo as interfaces com o espaço rural, alargando a sua conotação de ser apenas uma "indústria" vivendo da exploração de recursos naturais e da comercialização da cultura. Ganhou o turismo, nesta experiência aqui focalizada, uma nítida função social.

\section{Considerações Finais}

Com as visitas finalizadas na maioria das fazendas parceiras, em um primeiro momento da pesquisa, percebemos que há assimetrias nos problemas que atingem as unidades produtivas participantes do projeto abrangendo questões de preservação de patrimônio, material ou imaterial, além de discrepâncias no domínio dos conhecimentos específicos em gerenciamento do turismo sustentável e mesmo de práticas mais conservadoras, dentro de teorias da administração e gestão hoteleiras quanto a percepção de oportunidades e nichos de atuação possíveis como a educação patrimonial, por exemplo. Percebemos também que elas reúnem condições similares para o desenvolvimento de atividades turísticas diferenciadas, segundo questões específicas e identidades locais. No caso das fazendas históricas selecionadas pelo projeto em políticas públicas da FAPESP/CMU, percebe-se que de grandes propriedades produtoras de café ou cana, hoje se tornaram, pelo arrendamento de suas terras, propriedades relativamente pequenas ( 45 a 50 alqueires) com pouca ou nenhuma atividade agrícola. Nota-se uma clara perda de poder econômico de seus proprietários que encaram o 
turismo cultural e a educação patrimonial como a fonte principal de renda, na atualidade, para manter o patrimônio material que recebe as atividades ligadas ao patrimônio imaterial.

Assim através das entrevistas obtivemos duas visões sobre o patrimônio, sua história e condições de preservação e sustentabilidade: uma de classe mais elevada (o olhar dos proprietários) e outra a partir das classes populares (o olhar dos funcionários). Pudemos perceber a partir dos depoimentos de proprietários e gerentes das fazendas, mas também dos relatos de funcionários mais antigos das mesmas, três tipos diferentes de propriedade de acordo com sua utilização turística e educacional:

1- Em preparação para assumir atividades turísticas: Propriedades cujo patrimônio ainda está em fase de recuperação e as atividades turísticas e educacionais são planos para o futuro e necessitam de assessoria especializada para uma implantação com qualidade. (Exemplo: Fazenda Santa Úrsula, Jaguariúna - SP).

2- Turismo de habitação: Propriedades que praticam o "turismo de habitação", isto é, recebem os turistas na própria casa-sede acomodados em quartos livres (suítes ou com banheiro partilhado). As refeições são feitas com os membros da família do proprietário e os hóspedes podem acompanhar a realização das atividades agropecuárias cotidianas. Há assim uma proximidade com a família do proprietário e a curiosidade dos hóspedes e principalmente daqueles estrangeiros é constantemente suprida com esclarecimentos e exemplos concretos. Recebem também visitas diárias de grupos ou famílias de cidades próximas. (Exemplo: Fazenda Mandaguahy, Jaú - SP e Fazenda Chácara do Rosário, Itu - SP)

3- Hotel-fazenda: Propriedades que já possuem uma infra-estrutura diversificada e sofisticada para receber os turistas se caracterizando como Hotéis-Fazenda. Possuem estruturas para o lazer (piscina, cocheiras e cavalgada, quadras esportivas, passeios guiados, etc). Recebem hóspedes de classe média alta da capital e de cidades próximas, entre eles muitos estrangeiros. Recebem escolas que trabalham com educação patrimonial ou turistas no sistema day-use. (Exemplo: Fazenda Capoava, Itú - SP e Fazenda Bela Vista, Dourado - SP)

Nas reuniões da equipe do projeto foram discutidas também outras questões conexas à atratividade turística que podem ser desenvolvidas nas fazendas participantes - por exemplo, a relação entre hospitalidade e gênero e as formas diferenciadas de acolhimento que contemplem aspectos de integração com o imaginário rural. Para melhor desenvolver tais 
aspectos é necessário estabelecer uma maior conexão entre os elementos encontrados em cada fazenda participante e o que vem sendo apresentado e discutido pela bibliografia especializada visando a implementação futura de ações efetivas para o turismo cultural no espaço rural. Há algumas atividades desse tipo sendo desenvolvidas em fazendas como a Mandaguahy em Jaú - SP e a Quilombo em Limeira - SP, ao receber grupos de senhoras idosas provenientes de cidades próximas ou distantes, ou cavalgadas atraindo turistas que dominam a equitação e desejam roteiros mais amplos ou noturnos.

Além dos conhecimentos que os pesquisadores do projeto em políticas públicas FAPESP/CMU, de diferentes origens disciplinares possam fornecer aos proprietários das fazendas através de assessorias técnicas, sugerimos que os proprietários com maior experiência na adaptação das fazendas, principalmente aquelas com atividades turísticas já implementadas partilhem e discutam com seus pares as estratégias e táticas já desenvolvidas com sucesso nesse processo. A busca de parcerias com empresas, assim como com órgãos públicos poderia ser realizada em conjunto sob o "guarda-chuva" da Associação das Fazendas Históricas e com a orientação do projeto FAPESP/CMU.

A bibliografia da área da Gerontologia vem orientando nosso olhar durante a pesquisa de campo e vem demonstrando que os relacionamentos sociais influenciam a saúde e bem estar ao longo da vida e seus efeitos são evidentes em múltiplas dimensões da saúde e, portanto otimizá- los seria fonte para saúde e bem estar, também nos períodos finais da existência. Autores como Seeman e Berkman (1988) apontam que interações com amigos têm seus efeitos benéficos aumentados, pois estes relacionamentos são tidos como voluntários e como diferentes dos relacionamentos familiares, baseados em senso de obrigação. Assim nas visitas-dia a essas propriedades históricas, observamos que novos relacionamentos foram construídos entre os idosos o que conduziu a uma elevação da sua qualidade de vida, e ao desejo de repetição da experiência das visitas ao meio rural.

Trabalhamos a relação velhice e turismo em uma perspectiva educacional não-formal e não apenas na perspectiva operacional como é feito nas áreas mais tradicionais do turismo, como a da gestão hoteleira ou a da administração das empresas turísticas. É necessário assim, que os profissionais de turismo que em suas atividades lidam diretamente com idosos, conheçam as particularidades desse público e respeitem sua autonomia e suas limitações para evitar 
atitudes que reforcem os preconceitos a respeito do velho frágil. Pensem atividades diferenciadas e concomitantes voltadas aos diversos tipos de velhos que buscam tais fazendas históricas.

Podemos indicar como constatação principal dessa pesquisa em termos práticos, que as propostas de turismo cultural ou educação patrimonial para idosos devem ser elaboradas visando o atendimento de grupos reduzidos e formados segundo o desejo e a seleção dos próprios idosos, para que sua efetividade e prazer alcancem os níveis desejados. A oferta de turismo de massa $^{7}$ para essa faixa etária e para os espaços patrimoniais das fazendas se mostra desaconselhável, tanto para o público a ser atendido, que não verá suas demandas adequadamente respondidas como para os espaços turísticos a serem explorados que poderão sofrer sérios desgastes, em seu frágil patrimônio cultural rural.

\section{Referências}

AMORIM, Arantes R. A. 2007. Arruando pelos lugares: as excursões históricas e de Educação Patrimonial. In: Anais do Museu Histórico Nacional. Rio de Janeiro, v. 39. p. 345-361.

BACAL, Sarah. 2003. Lazer e o Universo dos Possíveis. São Paulo: Aleph.

BARRETO, Margarita. 2001. Turismo e Identidade Local: Uma visão antropológica. Campinas, SP: Papirus.

CAMPOS, Teresinha J. 2003. Lazer e Terceira Idade: contributos do Turismo no âmbito do Programa Clube da Melhor Idade. Dissertação (Mestrado). Programa de Pós-Graduação em Gerontologia. Universidade Estadual de Campinas. Campinas, SP: UNICAMP.

DAVIS, Kate. 2003. Biography as critical methodology. Newsletter Research Committee of ISA, n. 38, Utrecht University.

DIAS, Reinaldo. 2006. Turismo e Patrimônio Cultural. São Paulo: Saraiva.

DUARTE, Ana Maria P. 1994. Educação Patrimonial: Guia para professores, educadores, monitores de museu e tempo livres. Lisboa: Texto Editora.

FAUSTINO, Ricardo. F. 2006. O turismo em espaço rural como modo de valorização do Patrimônio Cultural: estudos de caso na média depressão periférica paulista: o caso dass Fazendas Capoava e Ibicaba. Tese (Doutorado). Programa de Pós - Graduação em Geografia. Faculdade de Filosofia, Letras e Ciências Humanas. Universidade de São Paulo. São Paulo: USP.

\footnotetext{
${ }^{7} \mathrm{O}$ turismo de massa abrange tanto o turismo de grupo como o turismo social. A diferença entre ambos reside no fato de que o primeiro tipo pressupõe indivíduos com disponibilidade para realizar viagens de férias com recursos próprios, sem qualquer forma de subvenção. O segundo tipo se caracteriza pelo vínculo com empresas públicas ou privadas - que organizam viagens turísticas, e as subvencionam total ou parcialmente. (BACAL, 2003)
} 
FRISCH, Michael. 1990. A Shared Authority: Essays on the Craft and Meaning of Oral and Public History. Albany: State University of New York.

FREIRE, Doia, PEREIRA Lígia L. 2002. História Oral, Memória e Turismo Cultural. In: MURTA MM, ALBANO C. (org). Interpretar o Patrimônio: um exercício do olhar. Belo Horizonte: Editora UFMG.

FUNARI, Pedro Paulo, PINSKY Jaime. 2005. Turismo e Patrimônio Cultural. São Paulo: Contexto.

GOELDNER, Charles; RITCHIE, Brent; MCINTOSH, Robert. 2002. Turismo: Princípios, práticas e filosofias. 8 ed. Porto Alegre: Bookman.

HARAHOUSOU, Yohana. Ocio como potencial para el desarrollo personal e social de las personas de avanzada edad. In: CABEZA MC. (org). Ocio e desarollo humano. Bilbao, Espanha, 2000.

HORTA, Maria de Lourdes P. 2005. Lições das coisas: o enigma e o desafio da educação patrimonial. In: Revista do Patrimônio Histórico e Artístico Nacional. Rio de Janeiro, n. 31, p. 221233.

HOOVER, Singer L., SIEGEL, James A. 1986. International demographic trends and perspectives on aging. San Diego: Cult. Gerontology.

JÚNIOR, Banducci. 2001. Turismo e Antropologia no Brasil: estudo preliminar. In: Junior AB; BARRETTO M. (orgs). Turismo e Identidade Local: uma visão antropológica. Campinas -SP: Editora Papirus.

KALACHE, Antony ; GRAY, James M. 1985. Health problems of older people in developing world. In: Pathy, M.S.J. Principles and pratice of geriatric medicine. New York.

LANG, Beatriz, S. G. 2001. História Oral: procedimentos e possibilidades. São Paulo: CERU.

MERCADANTE, Elisabeth F. 1998. A identidade e a subjetividade do idoso. In: Revista Kairós. Núcleo de Estudo e Pesquisa do Envelhecimento. Programa de estudos de pós - graduados da PUC/SP. São Paulo: Educ, 1 (1), pp. 50-67.

NERI, Anita, L. 1993. Qualidade de vida e idade madura. Campinas: Papirus.

2008. Saúde e envelhecimento: prevenção e promoção. In: Coselho Federal de Psicologia (org.). Envelhecimento e Subjetividade: desafios para uma cultura de compromisso social. Brasília: Conselho Federal de Psicologia.

PARK, Margareth, B. 2007. Entrevozes: crianças e velhos redimensionando práticas pedagógicas. in Revista Recriação - UFMGS, vol. 1, n.1, p. 67 - 72.

PELEGRINI, Sandra de Cássia A; FUNARI, Pedro Paulo. 2008. O que é patrimônio imaterial? São Paulo: Editora Brasiliense.

POSSATI, AJ. 2005. Turismo e Educação Patrimonial. Disponível em: <http://www.etur.com.br>. Acesso em: 15 de agosto de 2008>.

SOUZA, Heloisa Maria R. 2002. Turismo na Terceira Idade. Expectativas e Realidades. Dissertação (Mestrado). ECA - Escola de Comunicação e Artes. Universidade de São Paulo. São Paulo.

SIMSON, Olga, R. M. 2008. História Oral, memórias compartilhadas e empoderamento: um balanço de experiências de pesquisa. Texto apresentado em Simpósio realizado na Universidade de Concórdia no Canadá.

; PARK, Margareth, B; FERNANDES Renata. 2001. Educação não-formal: Cenários da criação. Campinas, SP: Editora da UNICAMP/Centro de Memória. 
; GIGLIO Zula, G. 2001. A arte de recriar o passado: história oral e velhice bem-sucedida. In: Desenvolvimento e Envelhecimento: Perspectivas Biológicas, Psicológicas, Sociológicas. NERI AN. (org). Campinas, SP: Papirus (Coleção Vivaidade).

ZANON, Elisa Roberta; MAGALHÃES, Leandro Henrique; BRANCO, Patrícia M. C. 2009. Educação Patrimonial: da teoria à prática. Londrina, PR: Editora UNIFIL.

Recebido em: 24/06/2010 (1 ${ }^{\text {a }}$ versão) $12 / 08 / 2010$ ( $2^{a}$ versão)

Aprovado em: 07/10/2010 